\title{
Catalyzed HTPB/HDI-Trimer Curing Reactions and Influence on Pot Life
}

\author{
Hui Ma ${ }^{1,2}$, Yucun Liu ${ }^{2, *}$, Jiahu Guo ${ }^{2,3, *(\mathbb{D}}$, Tao Chai ${ }^{2}$, Yanwu Yu ${ }^{2}$, Junming Yuan ${ }^{2}$, \\ Suming Jing ${ }^{2}$, Fawei Feng ${ }^{3, *}$, Lunchao Zhong ${ }^{4}$, Yanming Zhou ${ }^{5}$, Qin Zhang ${ }^{6}$ \\ and Guodong Wang ${ }^{2}$ \\ 1 School of Materials and Environmental Engineering, Chengdu Technological University, \\ Chengdu 611730, China; mahui20032011@163.com \\ 2 School of Environment and Safety Engineering, North University of China, Taiyuan 030051, China; \\ lyc2ct@vip.sina.com (T.C.); yyw7711@sina.com (Y.Y.); jmychina@163.com (J.Y.); j782855067@163.com (S.J.); \\ shiran1981@163.com (G.W.) \\ 3 Department of ESH, Science and Technology University of Sichuan Staff, Chengdu 610101, China \\ 4 Tsinghua Shenzhen International Graduate School, Tsinghua University, Shenzhen 518000, China; \\ qiangshou302@mail.tsinghua.edu.cn \\ 5 Shanxi Research Institute of Applied Chemistry, Taiyuan 030027, China; zymaizh@163.com \\ 6 Academic Affairs Office, Chengdu Technological University, Chengdu 611730, China; \\ zhangqincd2020@163.com \\ * Correspondence: lycnuc@sina.com (Y.L.); guojiahuphd@163.com (J.G.); fengfaweikzd@163.com (F.F.)
}

Received: 4 June 2020; Accepted: 5 November 2020; Published: 7 November 2020

\begin{abstract}
In this research, rheokinetics is used to study the curing reaction of hydroxyl terminated polybutadiene (HTPB) and trimer of hexamethylene-1,6-diisocyanate (HDI-trimer) with 1,4-diazabicyclo[2.2.2]octane (DABCO) as catalyst under different catalyst mass fraction. The results show that the pot life of the system depends on the catalyst mass fraction in the binder system. Furthermore, with increased catalyst mass fraction, the fitting diagram obtained by plotting $\mathrm{ln}$ (viscosity) versus curing time shows a better linear relationship. Therefore, the amount of catalyst required to achieve a certain pot life can be calculated through the formula. It is worth mentioning that the applicable pot life equations are proposed in the paper. From the equations, we find that under isothermal curing conditions at $35^{\circ} \mathrm{C}$, when the mass fraction of DABCO was $0.216 \mathrm{wt} . \%$, the pot life of the HTPB/HDI-trimer binder system reaches $4 \mathrm{~h}$.
\end{abstract}

Keywords: HTPB; HDI-trimer; DABCO; viscosity; pot life; rate constant for viscosity build-up

\section{Introduction}

Hydroxyl terminated polybutadiene (HTPB) is a telechelic liquid rubber with polybutadiene as the main chain and hydroxyl as the terminal, it is a most common type of polyol used to produce polyurethane (PU) [1]. This prepolymer have fine physical properties, such as low glass-transition temperature ( $\mathrm{Tg})$ and low viscosity [2]. Not only that HTPB reacts with isocyanates to form polyurethane elastomers also have good mechanical performance [3,4]. Accordingly, HTPB-based binder systems are widely applied in complex solid propellants and polymer bonded explosives (PBXs) $[5,6]$.

The vapor pressure of HDI is relatively low $\left(\sim 1.33 \mathrm{~Pa}, 25^{\circ} \mathrm{C}\right)$, and its volatility is comparatively high. Consequently, the production and application of HDI, usually have toxic and other hazardous effects on humans [7]. Thus, avoiding the industrial use of HDI is ideal from the environmental and health point of view. Generally, HDI is converted into HDI-biuret and HDI-trimer as commercial products. The chemical structure of HDI-biuret and HDI-trimer are shown in Figure 1. HDI-biuret, has an average functionality within the range of 3 . The average functionality of Desmordur HDI-biuret 
exceeds 3.6 [7]. Polyurethane products made from HDI-biuret possess good mechanical and solvent resistance properties, and HDI-biuret is included in the formula of castable PBXs and solid propellants. Compared with HDI-biuret, which usually is a compound of 3-functionality and 4-functionality, as show in Figure 1a, HDI-trimer has some special advantages, such as better storage stability than HDI-biuret and greater hardness of its PU products than products made from HDI-biuret. Furthermore, the viscosity of HDI-trimer $\left(\sim 2000 \mathrm{mPa} \cdot \mathrm{s}, 25^{\circ} \mathrm{C}\right)$ is much lower than that of HDI-biuret $(\sim 10,000 \mathrm{mPa} \cdot \mathrm{s}$, $25^{\circ} \mathrm{C}$ ) [7]. Most importantly, according to the latest research by Weems et al. [8], the use of cyclized isocyanates as a method of improving biostability has a promising prospect in the field of translating biomaterials toward clinical applications. Furthermore, HDI-trimer contains three isocyanate groups (NCO groups), which causes the viscosity of binder system increase rapidly in the later period of the curing reaction. This feature is good for shortening curing time and for avoiding solid formation sedimentation [9]. In the previous literatures [10-20], the study of HDI-trimer as curing agent and its influence on the pot life of HTPB-based binder systems in PBXs and solid propellants (i.e., processability of PBXs/propellant slurry) is seldom. Therefore, we employ cyclized isocyanate HDI-trimer as the curing agent in the present work.<smiles>O=NONC(=O)N(CCNO)C(=O)C(=O)NCCNO</smiles>

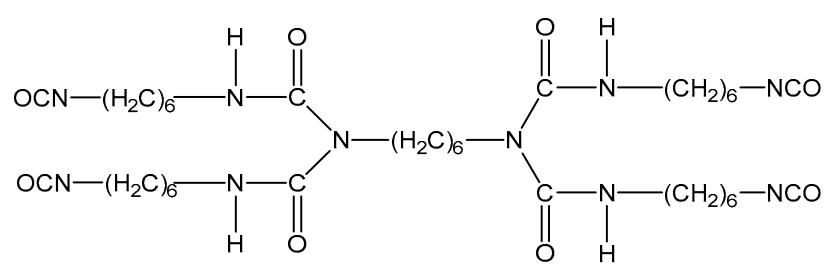

(a)<smiles>Cn1c(=O)n(CCNC=O)c(=O)n(CCNC(=O)[O-])c1=O</smiles>

(b)

Figure 1. Chemical structure of (a) HDI-biuret and (b) HDI-trimer.

The catalytic action of metallo-organic compounds, such as dibutyl tin dilaurate (DBTDL) and ferrric tris-acetylacetonate (FeAA), on the HAPB-based PU systems has been reported by different authors $[10,11,15-20]$. Usually, these metallo-organic catalysts have strong catalytic effect on the HTPB-based PU binder system, which significantly accelerates the curing reaction rate of the binder system. However, the accompanying relatively short pot life cannot satisfy certain application demands. Thus, looking for a catalyst with moderate catalytic activity is an important work for the researchers. As for the HTPB/HDI-trimer binder system, the catalytic activity of the tertiary amine catalyst 1,4-diazabicyclo[2.2.2]octane (DABCO) is lower than those of DBTDL and FeAA catalysts $[15,18,21]$. $\mathrm{DABCO}$ is a bis-heterocyclic tertiary amine compound with a unique cage structure, which has high catalytic activity on isocyanate groups [19]. To the best of our knowledge, the application of DABCO in the HTPB binder system and its influence on pot life has not been reported. As we all know that, pot life is a very important technological parameter in polyurethane processing [22]. The pot life of the binder system for solid rocket propellants and PBXs is usually defined as the consumed time when the system viscosity increases to $20,000-25,000 \mathrm{mPa} \cdot \mathrm{s}[23,24]$. The appropriate pot life of the propellants or PBXs slurry depends on the size of the grains that needed to casting. To produce small and medium grains, the pot life of the slurry needs to reach $4 \mathrm{~h}$, and the pot life needs to exceed $5 \mathrm{~h}$ when manufacturing large grains [23]. Adjusting and controlling the binder system's pot life plays a vital role in the processibility and late-stage properties of cured products $[25,26]$. Currently, the curing temperature of casting PBXs is relatively high $\left(60\right.$ to $\left.80^{\circ} \mathrm{C}\right)$ and the high curing temperatures usually lead to an unevenly distributed crosslinking density of the cured grains. In particular, during the cooling process 
after the high temperature curing, the casting grains will produce thermal stress (i.e., the shrinkage stress) inevitable, resulting in significantly decreased product performances. Therefore, reducing the curing temperature and determining the relationship between binder-system formulation and pot life under different curing temperature conditions are crucial for the manufacturing process and final performance.

In the present study, from the Arrhenius equation, we find that the main factors affecting the pot life of binder system are initial viscosity at temperature $T\left(\eta_{0}(T)\right)$ and rate constant for viscosity build-up at temperature $T\left(k_{\eta}(T)\right)$. The main influencing factors of initial viscosity $\eta_{0}(T)$ are the molecular weight of HTPB and the curing reaction temperature. From the viscosity build-up measurement, we found the initial viscosity of the binder systems and calculated the rate constant $k_{\eta}(T)$ values at $35{ }^{\circ} \mathrm{C}$. Furthermore, the function relationship between $k_{\eta}(T)$ and the mass fraction of catalyst was established. From the equation, we realized the goal that adjusting the binder system's pot life by changing the mass fraction of catalyst, which has great practical value in the manufacturing and product quality assurance.

\section{Materials and Methods}

\subsection{Materials}

Hydroxy-terminated polybutadiene (HTPB, number-average molecular weight $=2400 \mathrm{~g} \cdot \mathrm{mol}^{-1}$, 99\% purity) was purchased from Luoyang Liming Research Institute of Chemical Industry (Luoyang, China). The hydroxyl value of HTPB was $45.2 \mathrm{mg} \mathrm{KOH} \cdot \mathrm{g}^{-1}$. The calculation of hydroxyl value is referred to the literature [27]. Furthermore, the dispersity index (PDI) of HTPB was 2.32, which was determined by gel permeation chromatography (GPC). Trimer of hexamethylene diisocyanate (HDI-trimer, 99\% purity) purchased from Bayer (Leverkusen, Germany). The catalyst, 1,4-diazabicyclo[2.2.2]octane (DABCO, 99.9\% purity) was purchased from Tianjin Guangfu Fine Chemical Institute (Tianjin, China). The chemical structures of the HTPB and DABCO are shown in Figures 2 and 3.

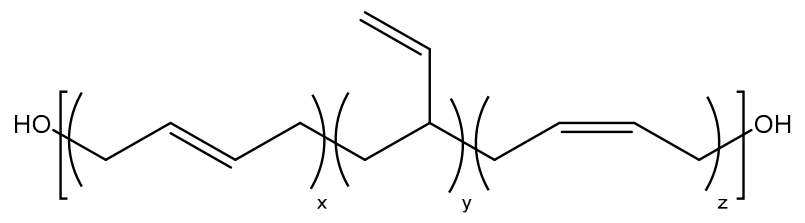

Figure 2. Chemical structure of HTPB.

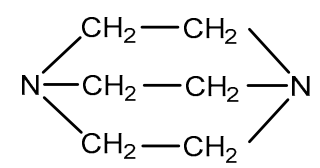

Figure 3. Chemical structure of DABCO.

HTPB was dehydrated under $0.05 \mathrm{mPa}$ vacuum at $100{ }^{\circ} \mathrm{C}$ for $2 \mathrm{~h}$ and placed in a dry-sealed bottle for storage. Other chemicals and solvents were used as received.

\subsection{Sample Preparation}

HTPB and HDI-trimer were accurately weighed with a stoichiometric ratio of 1:1 $(R=$ $n[\mathrm{NCO}] / n[\mathrm{OH}]=1)$ and mixed for $1 \mathrm{~min}$ at low-speed stirring $(500 \mathrm{rpm})$ by a mechanical stirrer. Catalyst DABCO was then added into the reaction system. Catalyst concentrations used in the binder system were $0 \mathrm{wt} . \%, 0.1 \mathrm{wt} . \%, 0.2 \mathrm{wt} . \%, 0.3 \mathrm{wt} . \%$, and $0.4 \mathrm{wt} . \%$, respectively. Afterwards, the reactants were stirred with a high-speed stirring $(1000 \mathrm{rpm})$ for $5 \mathrm{~min}$ at ambient temperature. The sample was vacuumed to remove bubbles for $5 \mathrm{~min}$ at $35^{\circ} \mathrm{C}$ once all reactants were thoroughly blended. The samples were then prepared for rheokinetic analysis. 


\subsection{Viscosity Measurements}

A Brookfield Viscometer SNB-1A (Shanghai Fangrui Instruments, Shanghai, China) with rotor number 29 and rotational speed of $0.5 \mathrm{rpm}$ was used to measure the viscosity build-up during the curing reaction. A thermostated water bath was employed to control the reaction temperature at $35{ }^{\circ} \mathrm{C}$ with an accuracy of $\pm 0.5{ }^{\circ} \mathrm{C}$. Then, approximately $20 \mathrm{~g}$ of the prepared sample was poured into a small-capacity sample vessel for viscosity measurements. The viscosity build-up was on-line monitored and measured at regular time intervals.

\subsection{FT-IR Measurements}

Fourier transform infrared (FTIR) spectra of the cured PU coating was analyzed by a Bruker Tensor 27 FTIR spectrometer (Bruker, Stuttgart, Germany) under nitrogen purging. Measurement was carried out in the range of $4000-500 \mathrm{~cm}^{-1}$ with a resolution of $0.5 \mathrm{~cm}^{-1}$ at room temperature.

\subsection{Experiment Principle}

In the curing process, viscosity increases as the reaction proceeds. The viscosity build-up of the binder system has an exponential relationship with the curing reaction time and can be adjusted to the Arrhenius model [28].

$$
\eta(t)_{T} / \eta_{0}(T)=\mathrm{e}^{k_{\eta}(T) t}
$$

where $\eta(t)_{T}$ is the binder system viscosity at temperature $T$ and at any given time $t, \eta_{0}(T)$ is the initial viscosity of the system at temperature $T, k_{\eta}(T)$ is the rate constant for viscosity build-up at temperature $T$, and $t$ is curing time.

Equation (1) describes the relationship between the binder system's viscosity build-up and the reaction time for an Arrhenius model. The pot life can be known to be a point on the curve. The function relating $t_{\text {pot life }}$ with viscosity $\eta_{\text {pot life }}$ can be derived as Equation (2).

$$
\eta_{\text {potlife }} / \eta_{0}(T)=\mathrm{e}^{k_{\eta}(T) t_{\text {potlife }}}
$$

where $\eta_{\text {pot life }}$ is the viscosity value above which the binder is considered too viscous for casting, $\eta_{0}(T)$ is the initial viscosity of the binder system at temperature $T, k_{\eta}(T)$ is the reaction rate constant $\mathrm{K}$ required to meet the set pot life, and $t_{\text {pot life }}$ is the time interval when the viscosity of the binder system reaches $\eta_{\text {pot life. }}$

Taking logarithm of both sides of Equation (1), we get Equation (3) [25]:

$$
\ln \left(\eta(t)_{T}\right)=\ln \left(\eta_{0}(T)\right)+k_{\mathfrak{\eta}}(T) t
$$

Taking logarithm of both sides of Equation (2), we get Equation (4):

$$
\ln \left(\eta_{\text {potlife }}\right)=\ln \left(\eta_{0}(T)\right)+k_{\eta}(T) t_{\text {potlife }}
$$

Plotting $\ln \left(\eta(t)_{T}\right)$ against $t$ should yield a straight line, which slope is the rate constant for viscosity build-up $k_{\eta}(T)$ and the intercept is the logarithm of the initial viscosity $\ln \left(\eta_{0}(T)\right.$ ).

\section{Results and Discussion}

Traditionally, HTPB binder is considered too viscous for casting when viscosities exceeding $20,000 \mathrm{mPa} \cdot \mathrm{s}$. In this study, pot life is defined as the time it takes for the viscosity of the HTPB binder system to increase to $20,000 \mathrm{mPa} \cdot \mathrm{s}$. From Equation (2), one can find that under isothermal conditions, the main factors influencing the pot life of the binder system are rate constant $k_{\eta}(T)$ and initial viscosity $\eta_{0}(T)$. Furthermore, $\eta_{\text {pot life }}$ has an exponential relationship with the rate constant for viscosity build-up $k_{\eta}$, and directly proportional with the initial viscosity $\eta_{0}$ of the binder system. Therefore, if the pot 
life is a fixed value, as the initial viscosity increases, the rate constant for viscosity build-up must be reduced, and vice versa.

The viscosities of HTPB at different temperatures were shown in Figure 4. From the figure, we can find that the viscosity of HTPB decreases exponentially with increased temperature. When the temperature increased from 15 to $60^{\circ} \mathrm{C}$, the viscosity of HTPB drops from 9949 to $1148 \mathrm{mPa} \cdot \mathrm{s}$. It is obviously that, under low temperatures condition, especially when the temperature was below $35^{\circ} \mathrm{C}$, changes in temperature have a greater impact on the viscosity of HTPB. Furthermore, HTPB is the major component of the binder system. As a consequence, the viscosity of HTPB greatly influences the initial viscosity of the binder system. Meanwhile, the viscosity of HDI-trimer is relatively low and does not change much at different temperatures. Considering that the dilution and viscosity reduction effect of the curing agent on the binder system is almost the same in the initial stage of the reaction, the change in viscosity of HTPB with temperature is approximately equal to the change in viscosity of the system with temperature. Thus, the initial viscosity of HTPB can be used as the approximate initial viscosity of the binder system.

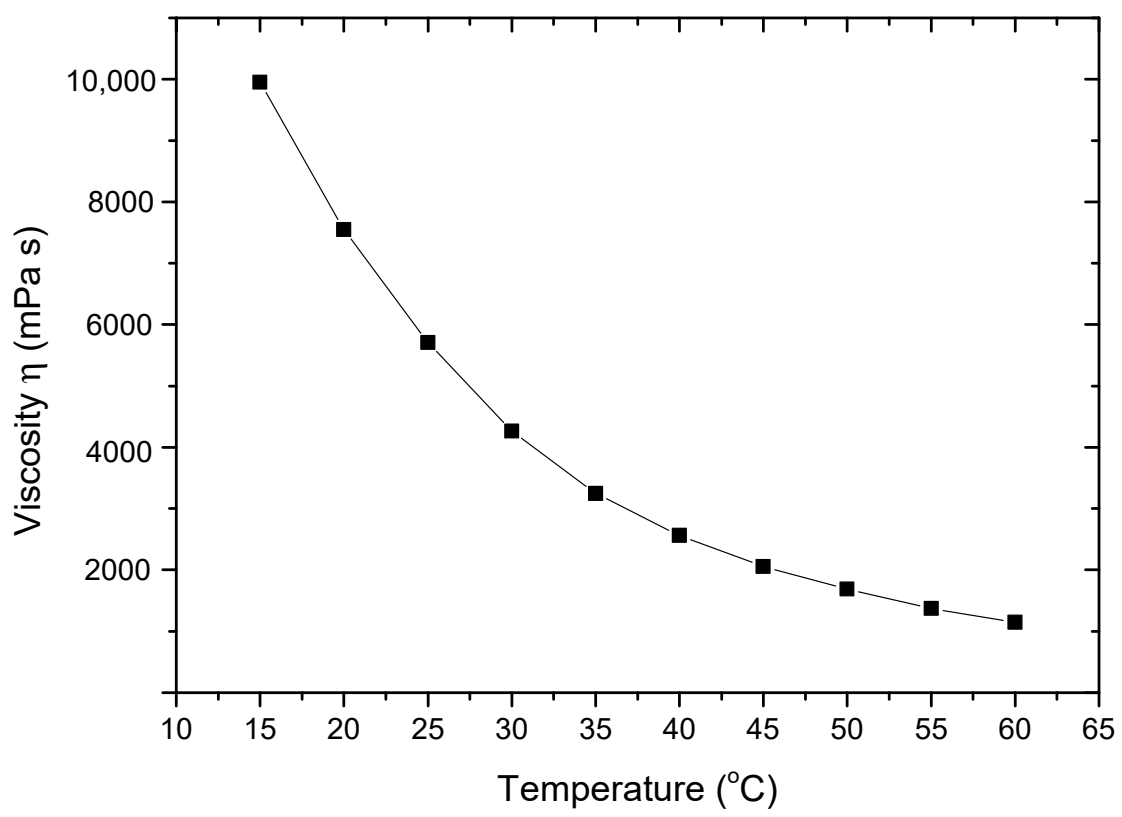

Figure 4. Viscosities of HTPB at different temperatures.

Accordingly, the desired rate constants for viscosity build-up $\left(k_{\eta}\right)$ that make the pot life reaches $4 \mathrm{~h}$ at different curing temperatures can be calculated. The results were listed in Table 1. From the data, we find that with decreased curing temperature, the initial viscosity of the HTPB-based binder system $\left(\eta_{0}\right)$ increases. As a consequence, in order to realize the same pot life $4 \mathrm{~h}$, the desired reaction rate constant $\left(k_{\eta}\right)$ decreases 24.87 times with decreased curing temperature from 60 to $15^{\circ} \mathrm{C}$. As the rate constant decreases, the curing time required after pot life is also prolonged. This characteristic makes the low-temperature curing not conducive to the prevention of grain sinking. However, in terms of the energy-saving and product final performance, lowering the curing temperature is a wise choice. Thus, for the purpose of accelerate the curing reaction, we chose to add catalyst in the binder system. Furthermore, through a series of pre-studies, the catalyst DABCO was selected for the following experiments due to its moderate catalytic activity.

DABCO with different mass fractions was added to the HTPB/HDI-trimer binder system. The viscosity build-up curves of the binder system at $35{ }^{\circ} \mathrm{C}$ were shown in Figure 5 . From the figure one can found that, with increased catalyst mass fraction, the growth of viscosity build-up was significantly accelerated and correspondingly, the pot life of the binder system was greatly shortened. At the same time, the initial viscosity of the system has not changed much. Therefore, the amount 
of catalyst has little effect on the initial viscosity of the binder system, but has a greater effect on the rheological reaction rate for viscosity build-up. Consequently, pot life can be controlled by adjusting the amount of catalyst to change the rate constant. From the figure, we can also find that in the beginning stage of the curing process the viscosity increases slowly. A slow increase in viscosity gives the slurry better flowability and is more conducive to casting. With the addition of the catalyst DABCO, the viscosity build-up of the binder system exponentially increased. Furthermore, this characteristic can prevent grain sinking to a large extent, which is meaningful for the final performance of the product.

Table 1. Rate constants for viscosity build-up $\left(k_{\eta}\right)$ that satisfy the pot life $4 \mathrm{~h}$ at different temperatures.

\begin{tabular}{cccccccc}
\hline No. & $\boldsymbol{T} /{ }^{\circ} \mathbf{C}$ & $\boldsymbol{\eta} \eta_{\mathbf{0}} / \mathbf{m P a} \cdot \mathbf{s}$ & $\boldsymbol{k}_{\boldsymbol{\eta}} / \mathbf{s}^{-\mathbf{1}}$ & $\mathbf{N o}$. & $\mathbf{T} /{ }^{\circ} \mathbf{C}$ & $\eta \eta_{\mathbf{0}} / \mathbf{m P a} \cdot \mathbf{s}$ & $\boldsymbol{k}_{\boldsymbol{\eta}} / \mathbf{s}^{\mathbf{1}}$ \\
\hline 1 & 15 & 9949 & $4.85 \times 10^{-5}$ & 6 & 40 & 2561 & $1.43 \times 10^{-4}$ \\
2 & 20 & 7547 & $6.77 \times 10^{-5}$ & 7 & 45 & 2057 & $1.58 \times 10^{-4}$ \\
3 & 25 & 5707 & $8.71 \times 10^{-5}$ & 8 & 50 & 1687 & $1.72 \times 10^{-4}$ \\
4 & 30 & 4262 & $1.07 \times 10^{-4}$ & 9 & 55 & 1373 & $1.86 \times 10^{-4}$ \\
5 & 35 & 3247 & $1.26 \times 10^{-4}$ & 10 & 60 & 1148 & $1.98 \times 10^{-4}$ \\
\hline
\end{tabular}

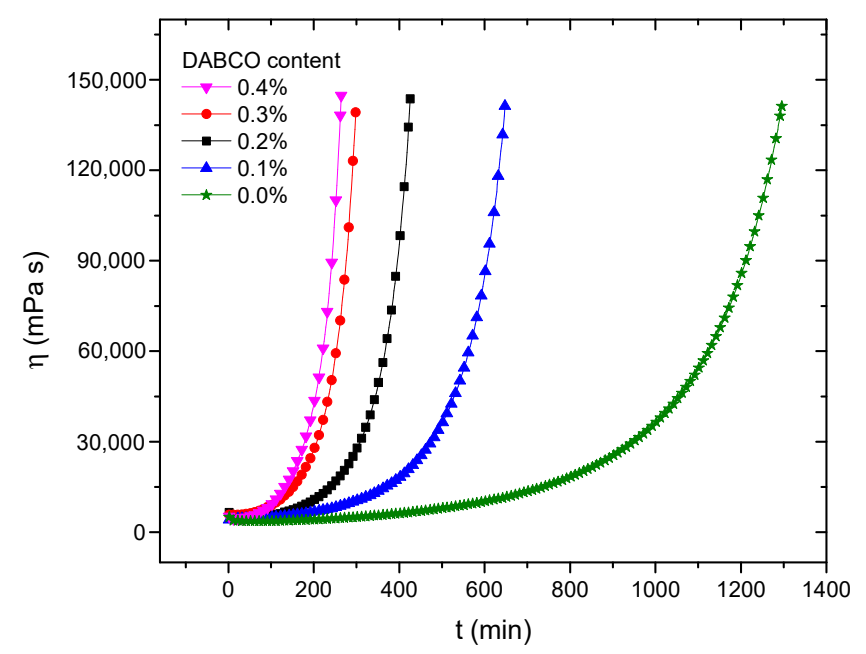

Figure 5. Viscosity build-up of the HTPB/HDI-trimer cure reaction in different mass fractions of the DABCO.

The logarithm of viscosity versus curing time for HTPB/HDI-trimer binder system with different DABCO concentrations at $35^{\circ} \mathrm{C}$ was shown in Figure 6. According to the study of Arangurent et al. [29], due to the large molecule of HTPB and allylic nature of all OH-groups in HTPB, the reactivities of $\mathrm{OH}$-groups present on different positions in HTPB are almost similar, which does not lead to obvious differences in reaction rate during curing. Therefore, this phenomenon is mainly due to the structure of HDI-trimer. HDI-trimer has three symmetrical NCO groups and similar reactivity of each NCO group. In the beginning stage of the curing reaction, with polymerization proceeds, the length of the molecular chain in the binder system increases gradually. When the reaction proceeds to a certain degree, the participation of a slight HDI-trimer in the reaction can cause rapid expansion of a polyurethane three-dimensional network, which leads to a rapid increase in viscosity and thence in the later stage of the curing reaction, the viscosity has skyrocketed. Thus, viscosity increases smooth and slow in the beginning and then exponentially increases.

Assuming that the viscosity curve of the curing process of the binder system in Figure 5 is subdivided into many small segments, each segment is fitted for Figure 6. The nitrogen atoms $\mathrm{N}$ in DABCO bind with isocyanate (NCO) to form an activated complex, which then reacts with hydroxyl to generate carbamic acid ester. In the early stage of the curing reaction, there are much more unreacted isocyanate (-NCO) groups compared with nitrogen atoms. The amount of complex 
formed is determined by the mass fraction of catalyst. Therefore, the mass fraction at the early stage of reaction has a great influence on the reaction rate (the fitting line slope algebraic difference is very large). As the reaction progresses, the amount of isocyanate $(-\mathrm{NCO})$ groups in the reactants continuously decrease, until they become less than nitrogen atoms. At this point, the amount of complex formed is determined by the amount of isocyanate $(-\mathrm{NCO})$ groups. The effect of the mass fraction of catalyst on the amount of complex formation gradually decreases, so the effect of catalyst mass fraction on reaction rate decreases with the progress of reaction (fitting line slope algebraic difference decreases). Given the offset of the curve above the fitting line, the early reaction rate constant $\left(k_{\text {early }}\right)$ is less than the late reaction rate constant $\left(k_{\text {late }}\right)$. Thus, the actual curve increasingly becomes a straight line with the mass fraction of catalyst increases as shown in Figure 6.

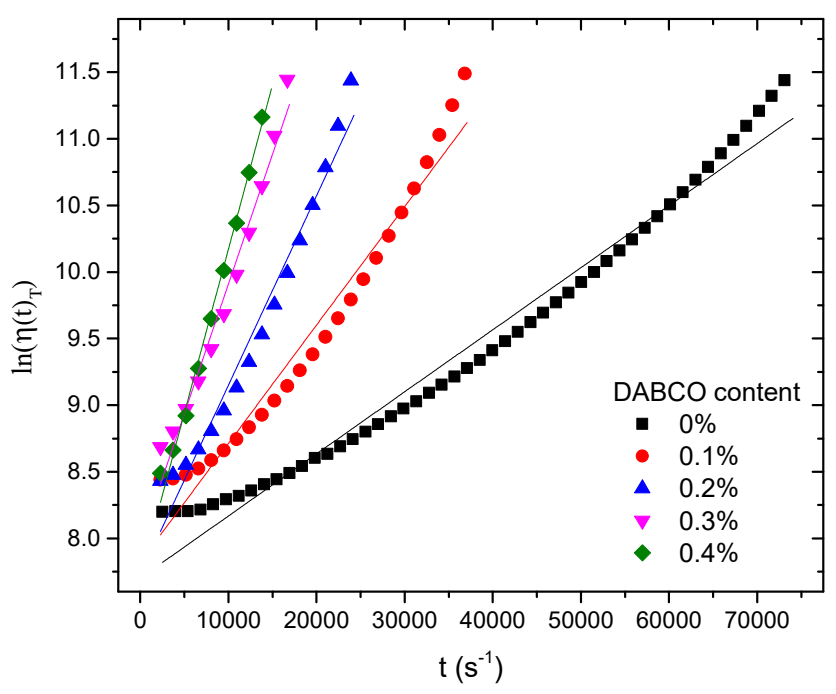

Figure 6. $\ln \left(\eta(t)_{T}\right)$ versus time for HTPB/HDI-trimer system in different mass fraction of the DABCO.

Equation (3) shows the fitting chart between $\ln \left(\eta(t)_{T}\right)$ and $t$, which yields a straight-line graph. The slope is $k_{\eta}(T)$ and the intercept is $\ln \left(\eta(T)_{0}\right)$. The rate constant $k_{\eta}(T), \ln \left(\eta(T)_{0}\right)$ and correlation coefficient $R^{2}$ under different catalyst mass fractions condition at $35^{\circ} \mathrm{C}$ was shown in Table 2. From the data, one can find that, with increased catalyst mass fraction, $k_{\eta}(T)$ gradually increases. When the DABCO mass fraction reached $0.4 \mathrm{wt} . \%$, the rheological rate constant $k_{\eta}$ rised to $2.46 \times 10^{-4} \mathrm{~s}^{-1}$, which was more than 5.2 times than that of none catalyst condition. Furthermore, the correlation coefficient $R^{2}$ of it was 0.9944 .

Table 2. Rheological parameters for the HTPB/HDI-trimer system in different mass fractions of the $\mathrm{DABCO}$ at $35^{\circ} \mathrm{C}$.

\begin{tabular}{cccc}
\hline Catalyst Mass Fractions/wt.\% & The Rate Constant $\boldsymbol{k}_{\boldsymbol{\eta}} / \mathbf{s}^{\mathbf{1}}$ & Correlation Coefficient $\boldsymbol{R}^{\mathbf{2}}$ & $\ln \boldsymbol{\eta}_{\mathbf{0}}$ \\
\hline 0.0 & $4.66 \times 10^{-5}$ & 0.9774 & 7.7026 \\
0.1 & $8.90 \times 10^{-5}$ & 0.9651 & 7.7231 \\
0.2 & $1.42 \times 10^{-4}$ & 0.9721 & 7.7280 \\
0.3 & $1.95 \times 10^{-4}$ & 0.9805 & 7.7218 \\
0.4 & $2.46 \times 10^{-4}$ & 0.9944 & 7.7089 \\
\hline
\end{tabular}

The fitting chart between $k_{\eta}(T)$ and catalyst mass fraction in Table 2 was shown in Figure 7. A straight line with a very high correlation coefficient $\left(R^{2}=0.9980\right)$ was observed. In the interval of $(0.0-0.4 \%)$ catalyst mass fraction, a good linear relationship exists, and the linear equation was shown in Equation (5).

$$
k_{\eta}(T)=4.276 \times 10^{-5}+0.05048 x
$$


where $k_{\eta}(T)$ is the rate constant for viscosity build-up and $x$ is the catalyst mass fraction.

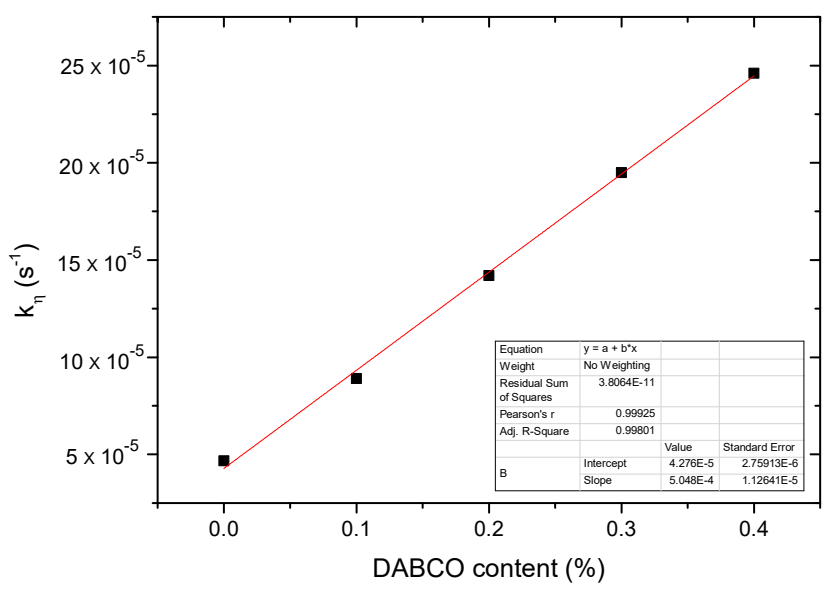

Figure 7. Fitting chart between $k_{\eta}(T)$ and mass fraction of the catalyst DABCO.

When we mixed HTPB with HDI-trimer, the curing reaction of the binder system has been started. Thus, measuring the initial viscosity in the beginning of the reaction was difficult. Hence, extrapolation method was used to solve the initial viscosity of each sample. The factors influencing the initial viscosity of binder system were as follows: catalyst mass fraction, HTPB molecular weight and mass fraction, curing agent mass fraction, and curing temperature. In this study, the amounts of HTPB and curing agent, as well as the curing temperatures, were also the same. Thus, the initial viscosity of binder system should be very similar. Experimental data were fitted to obtain different intercepts as shown in Table 2, and different initial viscosities can be obtained through these intercepts as shown in Table 3. From Table 3, one can find that, although the initial viscosities differ from 2214 to $2228 \mathrm{mPa} \cdot \mathrm{s}$, they were actually very close. Based on the coefficient of variation, we can determine that the discrete degree between each sample value and the sample average was very small, such that the sample value was very close to the sample average. Therefore, for each catalyst level, the same (average) initial viscosity was used. The average viscosity $2246 \mathrm{mPa} \cdot \mathrm{s}$ was taken as the initial viscosity of binder system.

Table 3. Initial viscosity for HTPB/HDI-trimer system in different mass fraction of DABCO at $35^{\circ} \mathrm{C}$.

\begin{tabular}{ccccc}
\hline $\begin{array}{c}\text { Catalyst Mass } \\
\text { Fractions/wt.\% }\end{array}$ & $\begin{array}{c}\text { Initial Viscosity } \\
\eta \eta_{0} / \mathbf{m P a} \cdot \mathbf{s}\end{array}$ & $\begin{array}{c}\text { Average Initial } \\
\text { Viscosity/mPa·s }\end{array}$ & $\begin{array}{c}\text { Standard } \\
\text { Deviation }\end{array}$ & $\begin{array}{c}\text { Coefficient of } \\
\text { Variation }\end{array}$ \\
\hline 0.0 & 2214 & & & \\
0.1 & 2260 & & & \\
0.2 & 2271 & 2246 & 23.93 & 0.01 \\
0.3 & 2257 & & & \\
0.4 & 2228 & & & \\
\hline
\end{tabular}

Table 1 indicated that the viscosity of HTPB at $35^{\circ} \mathrm{C}$ was $3247 \mathrm{mPa} \cdot \mathrm{s}$ and Table 3 indicated that the mean initial viscosity of the binder system was $2246 \mathrm{mPa} \cdot \mathrm{s}$. It is obvious that, at the same temperature, the viscosity of HTPB and the binder system was different. The reason is perhaps that, the curing agent produced a dilution effect in the binder system, for the viscosity of the curing agent was less than that of HTPB. As a consequence, the initial viscosity of the binder system was lower than that of HTPB at the same temperature.

Table 3 demonstrated that at $35^{\circ} \mathrm{C}$, the initial viscosity of the HTPB/HDI-trimer/DABCO system was approximately equal to the mean initial viscosity $k_{\eta}(T)$ of $2246 \mathrm{mPa} \cdot \mathrm{s}$, which can be substituted into $\eta_{0}(T)$ in Equation (2) to calculate $k_{\eta}(T)$. Furthermore, the results were shown in Table 4. 
Table 4. Rate constant for viscosity build-up $\left(k_{\eta}\right)$ that satisfies different pot lives for HTPB/HDI-trimer/DABCO system at $35^{\circ} \mathrm{C}$.

\begin{tabular}{cccccc}
\hline No. & Pot Life/s & The Rate Constant $\boldsymbol{k}_{\boldsymbol{\eta}} / \mathbf{s}^{\mathbf{- 1}}$ & No. & Pot Life/s & The Rat Constant $\boldsymbol{k}_{\boldsymbol{\eta}} / \mathbf{s}^{\mathbf{- 1}}$ \\
\hline 1 & 10,800 & $2.02 \times 10^{-4}$ & 4 & 12,960 & $1.69 \times 10^{-4}$ \\
2 & 11,520 & $1.90 \times 10^{-4}$ & 5 & 13,680 & $1.60 \times 10^{-4}$ \\
3 & 12,240 & $1.79 \times 10^{-4}$ & 6 & 14,400 & $1.52 \times 10^{-4}$ \\
\hline
\end{tabular}

From Table 4 one can find that different rate constant $k_{\eta}(T)$ that satisfies different pot lives. Furthermore, $k_{\eta}$ was substituted into Equation (5), which obtains the catalyst mass fractions of the HTPB/HDI-trimer/DABCO system at $35{ }^{\circ} \mathrm{C}$ that satisfies different pot lives. For example, if the $\mathrm{HTPB} / \mathrm{HDI}$-trimer/DABCO was taken as the binder system and the curing temperature was $35^{\circ} \mathrm{C}$. If the pot life must reach $4 \mathrm{~h}$ (i.e., 14,440 s), then, the mass fraction DABCO should be $0.216 \mathrm{wt} . \%$.

The infrared spectrum of the cured HTPB/HDI-trimer based PU coating film was displayed in Figure 8. As can be seen in the spectrum, the absence of a characteristic band at $2270 \mathrm{~cm}^{-1}$ confirmed the absence of residual NCO groups in the cured coating, which confirmed the completion of the reaction $[3,30]$.

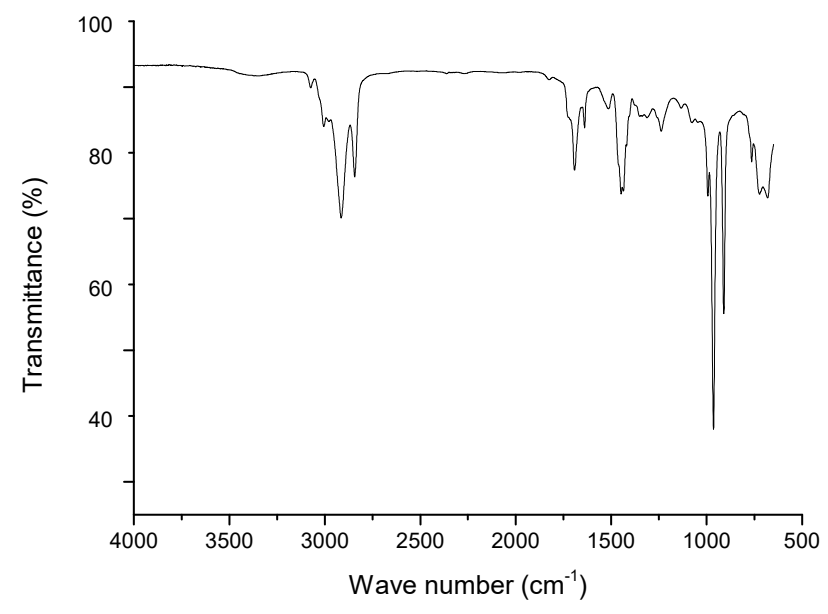

Figure 8. FT-IR spectra of the cured HTPB/HDI-trimer PU coating.

\section{Conclusions}

This study uses rheokinetics to investigate the curing reaction of the binder system of HTPB and HDI-trimer with DABCO as catalyst and aims to determine the optimal catalyst dosage to control the pot life of the binder system.

The viscosity of the HTPB/HDI-trimer/DABCO system increases slowly in the beginning stage and then increases exponentially. This characteristic induces the viscosity of the binder system to slowly increase during pot life, which gives the slurry better fluidity and renders it more conducive to casting. Furthermore, a rapid increase in viscosity after pot life prevents grain sinking, which is vital for the final performance of the product.

The Arrhenius equation shows that the influence factors of the binder system's pot life are the initial viscosity $\eta_{0}$ and the rheological reaction rate constant $k_{\eta}(T)$. According to the extrapolation method, the solved initial viscosity of the HTPB/HDI-trimer/DABCO binder system at $35^{\circ} \mathrm{C}$ is approximately equal to $\eta_{0}=2266 \mathrm{mPa} \cdot \mathrm{s}$. The pot life $(4 \mathrm{~h})$ and initial viscosity $(2266 \mathrm{mPa} \cdot \mathrm{s})$ are substituted into the equation to calculate the required reaction rate constant $1.52 \times 10^{-4} \mathrm{~s}^{-1}$. According to experimental data, $k_{\eta}(T)$ with catalyst mass fraction at $35^{\circ} \mathrm{C}$ is $k_{\eta}(T)=4.276 \times 10^{-5}+0.05048 x$. Thus, we find the principle that exists among the pot life, the curing temperature, and the amount of catalyst. This finding has significant potential value in the manufacturing process and product quality assurance. 
Author Contributions: Y.L. and T.C. conceived and designed the experiments; H.M., J.G., S.J., L.Z., and Y.Z. performed the experiments; Y.Y., J.Y., and G.W. analyzed the data; Q.Z. and F.F. contributed reagents/materials/analysis tools; H.M. and J.G. wrote the paper. All authors have read and agreed to the published version of the manuscript.

Funding: This work was supported by NSAF (Grant No. U1330131), Chengdu Technological University Start-up Project of Introducing Talents (Grant No. 2019RC010), Education Reform Project of Sichuan Province (Grant No. JG2018-1243), Safety Production Technology Project of Sichuan Province (Grant Nos. aj20180417153629 and aj20170518104846) and Shenzhen Free Exploration Project for Basic Research of Science and Technology Program (Grant No. JCYJ20180306174135470).

Acknowledgments: The authors are also grateful to Center of Big Data for Smart Environmental Protection (CDTU) for the cooperation.

Conflicts of Interest: The authors declare no conflict of interest.

\section{Abbreviations/Nomenclature}

$\begin{array}{ll}\text { DABCO } & \text { 1,4-diazabicyclo[2.2.2]octane } \\ \text { DBTDL } & \text { Dibutyl tin dilaurate } \\ \text { FeAA } & \text { Ferric tris-acetylacetonate } \\ \text { HTPB } & \text { Hydroxyl terminated polybutadiene } \\ \text { HDI } & \text { Hexamethylene-1,6-diisocyanate } \\ \text { HDI-trimer } & \text { Trimer of hexamethylene-1,6-diisocyanate } \\ \text { PBXs } & \text { Polymer bonded explosives } \\ \text { Tg } & \text { Low glass transition temperature } \\ k_{\eta}(T) & \text { Rate constant for viscosity build-up at temperature } T \\ \eta(t)_{T} & \text { Viscosity of the system at temperature } T \text { and at any given time } t \\ \eta_{0}(T) & \text { Initial viscosity of the system at temperature } T \\ \eta_{\text {pot life }} & \text { A viscosity level above which the HTPB-binder is considered too viscous for casting } \\ t_{\text {pot life }} & \text { Time when the viscosity of the binder system reaches } \eta_{\text {pot life }} \\ \mathrm{t} & \text { Curing time } \\ \mathrm{T} & \text { Curing temperature }\end{array}$

\section{References}

1. Toosi, F.S.; Shahidzadeh, M.; Ramezanzadeh, B. An investigation of the effects of pre-polymer functionality on the curing behavior and mechanical properties of HTPB-based polyurethane. J. Ind. Eng. Chem. 2015, 24, 166-173. [CrossRef]

2. Guo, J.; Chai, T.; Liu, Y.; Cui, J.; Ma, H.; Jing, S.; Zhong, L.; Qin, S.; Wang, G.; Ren, X. Kinetic research on the curing reaction of hydroxyl-terminated polybutadiene based polyurethane binder system via FT-IR measurements. Coatings 2018, 8, 175. [CrossRef]

3. Guo, J.-H.; Liu, Y.-C.; Jing, S.-M.; Ma, H.; Qin, N.; Zhou, H.; Yan, T.; He, W.-M. Synthesis and properties of a nano-silica modified environmentally friendly polyurethane adhesive. RSC. Adv. 2015, 5, 44990-44997.

4. Rocco, J.; Lima, J.; Frutuoso, A. TG studies of a composite solid rocket propellant based on HTPB-binder. J. Therm. Anal. Calorim. 2004, 77, 803-813. [CrossRef]

5. Krishnan, S.; Defence, R.D. Effect of burning rate modifiers on subatmospheric flame temperatures of AP/HTPB composite solid propellants. Sci. J. 1998, 48, 211. [CrossRef]

6. van der Heijen, A.E.D.M.; Leeuwenburgh, A.B. HNF/HTPB propellants: Influence of HNF particle size on ballistic properties. Combust. Flame 2009, 156, 1359. [CrossRef]

7. Yijun, L. Handbook of Raw Materials and Additives for Polyurethanes, 2nd ed.; Chemical Industry Press: Beijing, China, 2013.

8. Weems, A.C.; Carrow, J.K.; Gaharwar, A.K.; Maitland, D.J. Improving the oxidative stability of shape memory polyurethanes containing tertiary amines by the presence of isocyanurate triols. Macromolecules 2018, 51, 9078-9087. [CrossRef]

9. Zhang, L.; Wang, J.; Yang, X. Toughening modification of unsaturated polyester resin using HDI trimer. J. Wuhan Univ. Technol. 2009, 24, 627-630. 
10. Lucio, B.; de la Fuente, J.L. Rheokinetic analysis on the formation of metallo-polyurethanes based on hydroxyl-terminated polybutadiene. Eur. Polym. J. 2014, 50, 117-126. [CrossRef]

11. Gong, Y.; Yang, P.; Tao, F.; Zhang, D.; Guo, X.; Li, T. Kinetic and thermodynamic studies of the urethane reaction based on 1, 3-diazetidine-2, 4-dione and 4-(Tetrahydro-Pyran-2-yloxy)-butan-1-ol. J. Int. J. Polym. Anal. Charact. 2014, 19, 107-114. [CrossRef]

12. Rao, M.R.; Scariah, K.J.; Varghese, A. Evaluation of criteria for blending hydroxy terminated polybutadiene (HTPB) polymers based on viscosity build-up and mechanical properties of gumstock. Eur. Polym. J. 2000, 36, 1645-1651.

13. Hui, M.; Yucun, L.; Jiahu, G.; Tao, C.; Suming, J.; Yanming, Z.; Lunchao, Z.; Jun, D. Synthesis of a novel silica modified environmentally friendly waterborne polyurethane matting coating. Prog. Org. Coat. 2020, 139, 105441.

14. Arefinia, R.; Shojaei, A. On the viscosity of composite suspensions of aluminum and ammonium perchlorate particles dispersed in hydroxyl terminated polybutadiene-New empirical model. Colloid Interface Sci. 2006, 299, 962-971. [CrossRef]

15. Sekkar, V.; Raunija, T.S.K. Issues related with pot life extension for hydroxyl-terminated polybutadiene-based solid propellant binder system. Prop. Expl. Pyrotech. 2015, 40, 267-274. [CrossRef]

16. Bina, C.K.; Kannan, K.G.; Ninan, K.N. DSC study on the effect of isocyanates and catalysts on the HTPB cure reaction. J. Therm. Anal. Calorim. 2004, 78, 753-760. [CrossRef]

17. Hailu, K.; Guthausen, G.; Becker, W. In-situ characterization of the cure reaction of HTPB and IPDI by simultaneous NMR and IR measurements. Polym. Test 2010, 29, 513-519. [CrossRef]

18. Catherine, K.; Krishnan, K.; Ninan, K. A DSC study on cure kinetics of HTPB-IPDI urethane reaction. J. Therm. Anal. Calorim. 2000, 59, 93-100. [CrossRef]

19. Chen, A.T.; Wojcik, R.T. Polyurethane coatings for metal and plastic substrates. Met. Finish 2000, 98, $143-154$. [CrossRef]

20. Yang, P.F.; Yu, Y.H.; Wang, S.P. Kinetic studies of isophorone diisocyanate-polyether polymerization with in situ FT-IR. Int. J. Polym. Anal. Charact. 2011, 16, 584-590. [CrossRef]

21. Simanjuntak, F.S.H.; Choi, J.S.; Lee, G. Synthesis of glycerol carbonate from the transesterification of dimethyl carbonate with glycerol using DABCO and DABCO-anchored merrifield resin. Appl. Catal. B. 2015, 165, 642-650. [CrossRef]

22. Mahanta, A.K.; Dharmsaktu, I.; Pattnayak, P.K. Rheological behaviour of HTPB-based composite propellant: Effect of temperature and pot life on casting rate. Def. Sci. J. 2007, 57, 435. [CrossRef]

23. Daniel, M.A. Polyurethane Binder Systems for Polymer Bonded Explosives; No. DSTO-GD-0492; Defence Science and Technology Organisation-Weapons Systems DIV: Edinburgh, Australia, 2006.

24. Haska, S.B.; Bayramli, E.; Pekel, F. Mechanical properties of HTPB-IPDI-based elastomers. J. Appl. Polym. Sci. 1997, 64, 2347-2354. [CrossRef]

25. Sekkar, V.; Devi, K.A.; Ninan, K.N. Rheo-kinetic evaluation on the formation of urethane networks based on hydroxyl- terminated polybutadiene. J. Appl. Polym. Sci. 2001, 79, 1869-1876. [CrossRef]

26. Ackley, A.W.; Greenlee, T.W.; Gustavson, C. Bonding of composite propellant in cast-in-case rocket motors. J. Spacecr. Rockets 1966, 3, 413-418.

27. Weems, A.C.; Easley, A.; Roach, S.R.; Maitland, D.J. Highly cross-linked shape memory polymers with tunable oxidative and hydrolytic degradation rates and selected products based on succinic acid. ACS Appl. Bio Mater. 2019, 2, 454-463. [CrossRef]

28. Halley, P.J.; Mackay, M.E. Chemorheology of thermosets-An overview. Polym. Eng. Sci. 1996, 36, 593-609. [CrossRef]

29. Aranguren, M.I.; Williams, R.J.J. Kinetic and statistical aspects of the formation of polyurethanes from toluene diisocyanate. Polymer 1986, 27, 425-430. [CrossRef] 
30. Huang, H.; Zhang, D.; Fang, S.; Zhu, J.; Peng, X. Tuning the optical properties of high solid waterborne polyurethane from matt to anti-glare. Prog. Org. Coat. 2019, 126, 44-52. [CrossRef]

Publisher's Note: MDPI stays neutral with regard to jurisdictional claims in published maps and institutional affiliations.

(C) 2020 by the authors. Licensee MDPI, Basel, Switzerland. This article is an open access article distributed under the terms and conditions of the Creative Commons Attribution (CC BY) license (http://creativecommons.org/licenses/by/4.0/). 